\title{
Analisis Parameter Ber Dan C/N Dengan Lnb Combo Pada Teknologi Dvb-S2
}

\author{
Wahyu Pamungkas ${ }^{1}$, Eka Wahyudi ${ }^{2}$, Anugrah Ahmad Fauzi ${ }^{3}$ \\ ${ }^{123}$ Sekolah Tinggi Teknologi Telematika Telkom Purwokerto \\ 1'wahyu@st3telkom.ac.id, ${ }^{2}$ ekawahyudi@gmail.com, ${ }^{3}$ Anugrah.AhmadF@ telkomsel.belackberry.com,
}

\begin{abstract}
Abstrak - Instalasi antena parabola berfungsi untuk memudahkan pada saat pengarahan pointing antena ke satelit yang dituju. Permasalahan yang diketahui yaitu bagaimana perilaku parameter Bit Error Rate (BER) dan Carrier to Noise (C/N) pada LNB Combo yang menggunakan teknologi DVB-S2. Setelah instalasi antena parabola dilakukan dan sukses, maka langkah selanjutnya yaitu melakukan pointing antena. Pointing antena diarahkan pada posisi satelit yang akan dituju. Satelit yang akan dituju yaitu Palapa D menggunakan frekuensi C-Band sedangkan Ku-Band diarahkan pada satelit NSS 6. Setelah pointing selesai dilakukan maka langkah selanjutnya yaitu menghubungkan dengan Digital Video Broadcasting Satellite Second Generation (DVB-S2). DVB-S2 merupakan receiver. Parameter yang diamati yaitu parameter BER dan C/N. Parameter BER merupakan perbandingan dengan jumlah bit yang diterima secara tidak benar dengan jumlah bit informasi yang ditransmisikan pada selang waktu tertentu. Parameter $\mathbf{C} / \mathbf{N}$ merupakan perbandingan nilai pada carrier yang diterima dengan nilai sinyal noise yang dihasilkan dalam suatu link. Diperlukan juga Low Noise Block (LNB) Combo yang berguna untuk mentransmisikan sinyal ke receiver. LNB yang digunakan merupakan LNB Combo, dimana dua buah frekuensi yakni C-Band dan KU-Band menjadi satu dalam sebuah LNB. Setelah melakukan pengukuran dan melihat hasil pengukuran, dapat disimpulkan bahwa LNB Combo berpengaruh pada sinyal C-Band yang dihasilkan, sinyal C-Band akan mengalami penurunan kualitas, ini dibuktikan dari hasil pengukuran yang telah dilakukan bahwa nilai parameter C/N dan BER pada Ku-Band lebih baik daripada nilai parameter $\mathrm{C} / \mathrm{N}$ dan BER pada $\mathrm{C}$ Band.
\end{abstract}

Kata kunci : Parameter BER, Parameter C/N, DVB-S2, LNB Combo.

\section{PENDAHULUAN}

\section{A. Latar belakang}

Perkembangan dunia telekomunikasi yang sudah sedemikian canggih mempengaruhi berbagai kebutuhan masyarakat akan layanan hidup yang semakin meningkat, termasuk dalam bidang telekomunikasi. Bidang telekomunikasi yang saat ini sedang berkembang pesat yaitu sistem komunikasi satelit. Sistem komunikasi satelit sangat dibutuhkan sekali bagi masyarakat modern ini karena kecepatannya yang tinggi dan transmisi lebih jauh dari pada menggunakan kabel fiber optic atau menggunakan radio microwave. Terlebih lagi wilayah Indonesia yang secara geografis terdiri dari gugusan gugusan pulau maka sistem komunikasi satelit di Indonesia sangat cocok digunakan.

Dengan adanya sistem komunikasi satelit di Indonesia, komunikasi yang dilakukan antar pulau akan lebih efisien dan efektif. Sistem komunikasi satelit terdiri dari space segment yang mana merupakan bagian yang berada di angkasa dalam hal ini yaitu satelit. Dan ground segment, ground segment ini berada di bumi atau stasiun bumi. Ground segment pada dasarnya dikategorikan menjadi dua yaitu stasiun pengendali utama yang mana berfungsi untuk mengontrol dan mengendalikan satelit dari bumi dan stasiun bumi yang berfungsi untuk komunikasi.

Stasiun bumi yang digunakan untuk komunikasi dua arah baik untuk transmitter maupun untuk receiver berdasarkan penempatannya dibedakan menjadi dua yaitu Indoor Unit (IDU) dan Outdoor Unit (ODU). Pada perangkat IDU terdapat modem, multiplexer, baseband processor, alarm dan control power supply. Sedangkan pada perangkat $O D U$ terdapat Up/Down Converter, Solid State Power Amplifier (SSPA) atau High Power Amplifier (HPA), Power Supply Unit (SPU) dan antena sub-sistem yang terdiri dari reflector, feedhorn, Low Noise Amplifier (LNA).

Pada stasiun bumi yang digunakan untuk satu arah yang sering digunakan untuk menerima siaran televisi ataupun sebagai radio, perangkat - perangkatnya terdiri dari antena reflector, Low Noise Block (LNB), kabel coaxial. Antena berfungsi menerima sinyal berupa gelombang elektromagnetik yang bermodulasi RF dari satelit. Low Noise Block (LNB) berfungsi menerima gabungan sinyal yang dipantulkan dari piringan/dish. Kabel coaxial berfungsi sebagai penghubung dari LNB ke perangkat yang menampilkan siaran televisi. Tipe-tipe LNB dibedakan berdasarkan dengan frekuensi. Pada 
masing - masing LNB ini hanya dapat digunakan untuk satu band frekuensi.

Dengan adanya perkembangan zaman dalam satu buah LNB terdapat 2 buanh tipe LNB yang dinamakan LNB combo. LNB combo terdiri dari LNB C-Band dan LNB KU-Band sehingga dapat saling melengkapi kekurangan masing-masing LNB. LNB $\mathrm{C}$-Band mempunyai frekuensi up-link $4 \mathrm{GHZ}$ dan frekuensi downlink 6 GHZ. Sedangkan pada LNB KU-Band mempunyai frekuensi yang lebih besar dari pada C-Band, yaitu 12 GHZ sampai dengan $14 \mathrm{GH}$. Tetapi, LNB KU-Band sangat sensitif terhadap cuaca terutama hujan.

Sistem komunikasi satelit memiliki sebuah parameter yang menunjukkan kinerja dari sebuah sistem komunikasi satelit, parameter tersebut adalah parameter link budget. Parameter pada link budget diantaranya Bit Error Rate (BER) dan Carrier To Noise $(\mathrm{C} / \mathrm{N})$. BER adalah perbandingan dengan jumlah bit yang diterima secara tidak benar dengan jumlah bit informasi yang ditransmisikan pada selang waktu tertentu. Parameter BER adalah parameter yang digunakan untuk menilai performance transmisi digital.

Semakin rendah parameter BER yang dihasilkan oleh suatu transmisi digital, semakin baik performance transmisi digital tersebut. Parameter $\mathrm{C} / \mathrm{N}$ adalah parameter yang nantinya akan membandingkan antara carrier dengan besarnya noise yang diterima dalam sebuah link. Untuk dapat mengetahui parameter $\mathrm{C} / \mathrm{N}$ dan BER diperlukan sebuah alat penerima (receiver) yaitu Digital video broadcasting-Satellite Second Generation (DVB-S2).

Pada umumnya masyarakat menggunakan LNB C-Band atau LNB KU-Band saja untuk mendapatkan layanan televisi. Dengan banyaknya siaran televisi yang dapat diakses oleh masyarakat dan siaran televisi tersebut tidak hanya dalam band frekuensi yang sama maka dibutuhkan LNB yang efektif dan efisien yaitu LNB combo. Pemasangan LNB combo pada antena maka dapat memaksimalkan jumlah siaran televisi dengan band frekuensi yang berbeda dalam satu antena parabola. Masyarakat selain menginginkan siaran televisi yang banyak tetapi juga menginginkan gambar yang diperoleh kualitasnya lebih baik maka dari itu menggunakan Motion Pictures Expert Group Version 4 (MPEG-4) pada format sistemnya.

\section{DASAR TEORI}

\section{A. Sistem Komunikasi Satelit}

Satelit dapat dikatakan suatu objek yang mengitari bumi. Beberapa objek yang dapat dikatakan sebagai satelit antara lain bulan, meteor dan benda-benda angkasa lainnya. Satelit dibagi menjadi dua, yaitu satelit alami dan satelit buatan. Salah satu satelit alami adalah bulan yang telah ada dan mengitari bumi sejak terciptanya alam semesta. Sementara satelit buatan yaitu satelit yang diciptakan oleh manusia yang salah satu fungsinya untuk melakukan komunikasi antar pulau maupun antar negara ${ }^{[10]}$.

Gagasan tentang komunikasi satelit pertama kali dicetuskan oleh Arthut C Clarke pada Tahun 1945, beliau yang juga seorang pengarang fiksi ilmiah berpendapat dengan menempatkan satelit pada orbit geostationer pada ketinggian $35.786 \mathrm{~km}$ diatas permukaan bumi akan mempunyai kecepatan sudut yang sama dengan kecepatan putaran bumi. Dengan demikian posisi satelit akan selalu tetap terhadap setiap titik di permukaan bumi. Satelit yang berada pada orbit ini bergerak dari arah timur ke arah barat mengikuti arah rotasi bumi ${ }^{[5]}$.

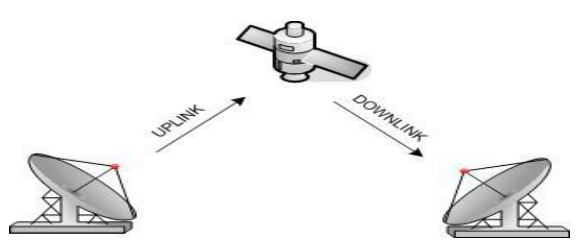

Gambar 1. Konfigurasi sIstem komunikasi satelit ${ }^{[1]}$

\section{B. Parameter BER dan $C / N$}

Sistem komunikasi satelit memiliki sebuah parameter yang menunjukkan kinerja dari sebuah sistem komunikasi satelit, parameter tersebut adalah parameter link budget. Parameter pada link budget diantaranya Bit Error Rate (BER) dan Carrier To Noise $(\mathrm{C} / \mathrm{N})$. Parameter yang akan diukur kali ini adalah C/N (Carrier to Noise) dan BER (Bit Error Rate).

\section{Carrier to Noise $(\mathrm{C} / \mathrm{N})$}

Merupakan perbandingan nilai pada carrier yang diterima dengan nilai sinyal noise yang dihasilkan dalam suatu link. Harga $\mathrm{C} / \mathrm{N}$ ditentukan dan dipilih berdasarkan jenis dan fasilitas telekomunikasi yang akan diterapkan.

\section{Bit Error Rate (BER)}

Merupakan perbandingan dengan jumlah bit yang diterima secara tidak benar dengan jumlah bit informasi yang ditransmisikan pada selang waktu tertentu. Parameter BER adalah parameter yang digunakan untuk menilai performance transmisi digital. Semakin rendah parameter BER yang dihasilkan oleh suatu transmisi digital, semakin baik performance transmisi digital tersebut.

\section{E. Low Noise Block}

LNB merupakan perangkat dalam komunikasi satelit berbentuk rongga resonator, dimana dalam sistem DVB-S2 berfungsi menerima sinyal satelit dari arah antena parabola dan memproses sinyal tersebut. Selain itu LNB juga berfungsi menguatkan sinyal dan mengubah frekuensi dari satelit menjadi frekuensi 
yang lebih rendah sebelum dikirim ke perangkat modem DVB-S2 maupun satellite meter ${ }^{[4]}$.

Pada stasiun bumi yang digunakan untuk satu arah yang sering digunakan untuk menerima siaran televisi ataupun sebagai radio, perangkat - perangkatnya terdiri dari antena reflector, Low Noise Block (LNB), kabel coaxial. Antena berfungsi menerima sinyal berupa gelombang elektromagnetik yang bermodulasi RF dari satelit. Low Noise Block (LNB) berfungsi menerima gabungan sinyal yang dipantulkan dari piringan/dish.

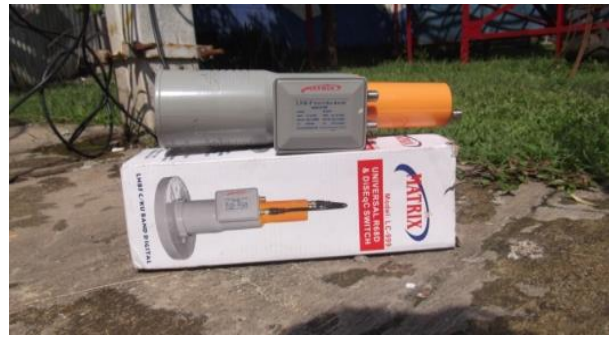

Gambar 2. Low Noise Block

F. Digital Video Broadcasting Second Generation.

Untuk dapat mengetahui parameter $\mathrm{C} / \mathrm{N}$ dan BER diperlukan sebuah alat penerima (receiver) yaitu Digital video broadcasting-Satellite Second Generation (DVB-S2). DVB-S2 merupakan pengembangan dari DVB-S, peningkatan DVB-S2 bertepatan dengan pengenalan HDTV dan MPEG-2 atau MPEG-4 video codecs. DVB-S2 berdasarkan standart DVB-S yang digunakan untuk melakukan broadcasting pada satelit, dan standart DVB-DSNG yang digunakan oleh mobile unit untuk mengirimkan external footage kembali ke stasiun televisi.

Kelebihan DVB-S2 adalah pada sisi kapasitasnya yang lebih besar, hingga $30 \%$ lebih baik dari pada DVB-S. DVB-S2 juga sangat flexible dan dapat bekerja pada transponder seperti apapun. DVB-S2 tidak hanya terbatas pada MPEG-2 melainkan dapat menangani format audio dan video yang lebih maju seperti MPEG-4.

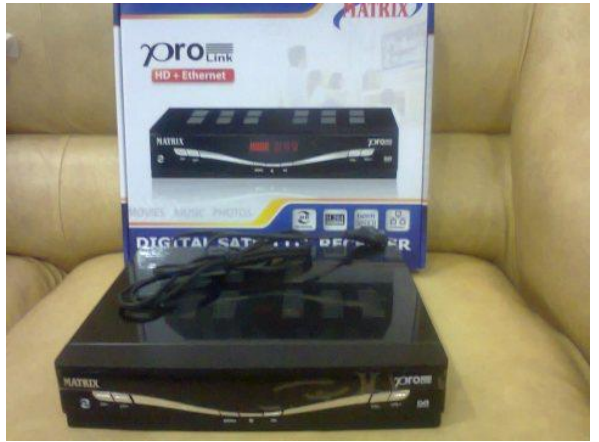

Gambar 3. DVB-S2

\section{G. Antena}

Antena merupakan perangkat media transmisi tanpa kabel yang memanfaatkan udara atau ruang bebas sebagai media penghantar. Dalam suatu sistem transmisi terdapat dua Antena, yaitu antena pengirim $(T x)$ dan antena penerima $(R x)$. Fungsi dari Antena pengirim yaitu memancarkan serta merubah gelombang elektromagnetik terbimbing menjadi gelombang elektromagnetik ruang bebas. Sedangkan Antena penerima berfungsi menerima serta merubah gelombang elektromagnetik ruang bebas menjadi gelombang elektromagnetik terbimbing ${ }^{[6]}$.

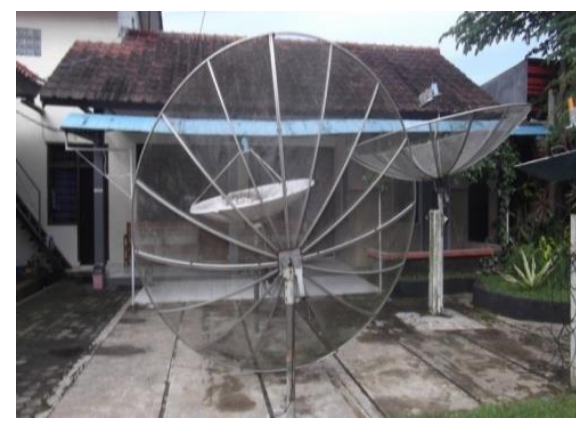

Gambar 4.. Antena Parabola

\section{H. Sudut Azimut dan Elevasi}

Pada sistem komunikasi satelit penempatan stasium bumi harus pada posisi yang tepat dan berada pada daerah cakupan satelit afar sinyal yang dikirim dapat diterima satelit dan dipancarkan kembali ke stasium bumi penerima. Untuk menempatkaan stasiun bumi pada pisisi yang tepat agar dapat berkomunikasi dengan satelit, harus diketahui sudut azimuth dan sudut elevasi agar daya yang dipancarkan atau yang diterima dapat optimal, aplikasi sudut azimuth dan elevasi dapat dilihat pada gambar 2.16 .

Sudut elevasi merupakan sudut yang dihasilkan oleh arah utara sebenarnya dari titik yang dipasang antena dengan arah vertikal antena terhadap satelit. Sedangkan sudut azimuth merupakan sudut putar pada arah horizontal, dimana arah utara digunakan sebagai referensi sudut nol (0).

\section{METODOLOGI}

\section{A. Menentukan Sudut Azimuth}

Sebelumnya, antena parabola harus terhindar dari penghalang, jika terdapat penghalang pada antena maka akan mengganggu proses penerimaan sinyal dari satelit.

\section{B. Menentukan Sudut Elevasi}

Antena akan diatur sesuai sudut elevasi agar mengarah menuju satelit yang akan digunakan. Sudut elevasi penting dilakukan agar mendapatkan kualitas sinyal yang baik dan kuat karena mengarah dengan tepat menuju satelit yang akan digunakan.

\section{Pointing Antena}

Pointing Antena dapat dilakukan dengan menggunakan alat bantu angel level, satellite meter 2200, kunci 19 untuk mengatur cannester, kunci 22 untuk mengatur sudut elevasi serta kunci 14 dan 18 
untuk mengatur sudut Azimuth. Angel level berfungsi untuk membantu posisi deraja't kemiringan ketika melakukan pointing antena ke satelit Palapa-D dan Satelit NSS 6.

\section{Menghubungkan Antena dengan DVB-S2}

Pada tahap ini antena akan dihubungkan langsung dengan DVB-S2 dengan menggunakan kabel coaxial. Kemudian kabel audio-video dihubungkan dari DVBS2 menuju televisi.

\section{E. Pengamatan Parameter BER dan $\mathrm{C} / \mathrm{N}$}

Pada tahap ini adalah tahap terakhir dimana akan melakukan pengamatan terhadap Parameter BER dan $\mathrm{C} / \mathrm{N}$ dari hasil pointing antena yang telah dilakukan sebelumnya.

\section{ANALISA DAN PEMBAHASAN}

Proses instalasi antena parabola harus dilakukan sesuai prosedur yang benar, agar dapat menerima sinyal dari satelit secara maksimal. Hal ini juga perlu ditunjang oleh peralatan pendukung yang dalam kondisi baik, sehingga tidak terjadi kesalahan saat instalasi. Sebelumnya harus menentukan dahulu satelit mana yang akan digunakan, dengan syarat foot print dari satelit tersebut harus mencakup pada posisi antena stasiun bumi itu diletakkan.

Setelah dilakukan pengukuran terhadap parameter Bit Error Rate (BER) dan Carrier To Noise (C/N) pada satelit Palapa-D dan Satelit NSS-6, dapat diambil kesimpulan seperti pada tabel berikut.

Tabel 1. Hasil Pengukuran C/N

\begin{tabular}{|c|c|c|c|c|c|c|c|}
\hline \multirow{2}{*}{ C/N } & \multicolumn{7}{|c|}{ Sample } \\
\cline { 2 - 8 } & 1 & 2 & 3 & 4 & 5 & 6 & 7 \\
\hline $\begin{array}{c}\text { TvOnE } \\
(\text { dB) }\end{array}$ & 6 & 6.2 & 6.4 & 6.4 & 5.9 & 6.3 & 6.4 \\
\hline $\begin{array}{c}\text { Bali Tv } \\
(\text { dB })\end{array}$ & 6 & 6.8 & 6.8 & 6.8 & 6.7 & 6.8 & 6.7 \\
\hline $\begin{array}{c}\text { MNC } \\
\text { Tv } \\
\text { (dB) }\end{array}$ & 7 & 6.8 & 6.8 & 6.8 & 6.8 & 6.7 & 6.9 \\
\hline
\end{tabular}

Pada tabel di atas berisikan nilai parameter $\mathrm{C} / \mathrm{N}$ yang telah diukur dengan alat ukur Satellite Meter 2200. Pengambilan sample diambil sebanyak 7 kali pada setiap Channel agar hasil pengamatan lebih detail. Channel yang dipilih adalah Tv One, Bali Tv, MNC Tv yang berada pada jangkauan satelit Palapa$\mathrm{D}$ dengan frekuensi C-Band. Dapat dilihat pada ketiga Channel yang diambil samplenya, nilai $\mathrm{C} / \mathrm{N}$ dari masing-masing Channel tidak terlalu mengalami penurunan maupun kenaikan yang signifikan.

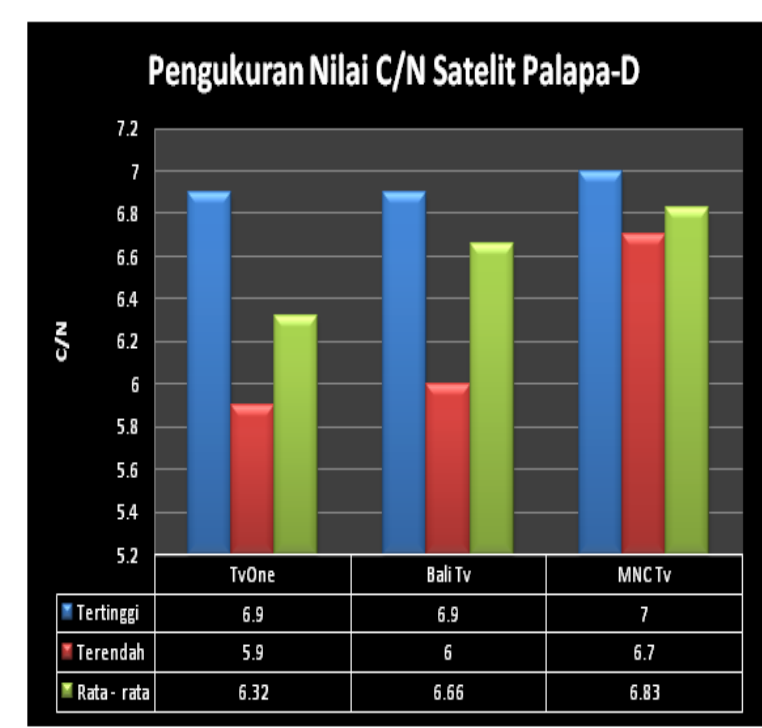

Gambar 5 Pengukuran Nilai C/N Satelit Palapa D

Pada Gambar di atas merupakan tampilan parameter pengukuran $\mathrm{C} / \mathrm{N}$ pada satelit Palapa-D dalam bentuk grafik dimana nilai yang ditampilkan adalah nilai $\mathrm{C} / \mathrm{N}$ tertinggi, terendah, rata-rata, serta nilai yang sering muncul pada ketiga Channel yang telah ditetapkan yakni TvOne, Bali Tv, dan MNC Tv.

Berdasarkan hasil pengukuran pada sampel hari ke-6 dan ke-7 untuk parameter BER dan $\mathrm{C} / \mathrm{N}$ pada satelit Palapa-D dan NSS-6 pada gambar di bawah, dapat disimpulkan bahwa kualitas sistem dari Channel pada satelit NSS-6 dengan frekuensi Ku-Band lebih baik dari pada kualitas sistem dari Channel pada satelit Palapa-D yang menggunakan frekuensi CBand. Ini dibuktikan dari nilai BER pada ketiga Channel pada satelit Palapa-D lebih tinggi dari pada nilai BER pada ketiga Channel pada satelit NSS-6. Kembali pada dasarnya bahwa BER dapat digunakan sebagai acuan untuk mengindikasikan bagus atau tidaknya suatu sistem dari Channel televisi tersebut. Dimana semakin besar nilai BER, maka semakin buruk sistem Channel televisi tersebut. Selanjutnya pada ketiga Channel pada satelit NSS-6 memiliki nilai $\mathrm{C} / \mathrm{N}$ yang lebih tinggi dari pada nilai $\mathrm{C} / \mathrm{N}$ untuk ketiga Channel pada satelit Palapa-D. Kembali pada dasarnya bahwa semakin tinggi nilai $\mathrm{C} / \mathrm{N}$ maka akan semakin bagus pula sistem dari Channel televisi tersebut.

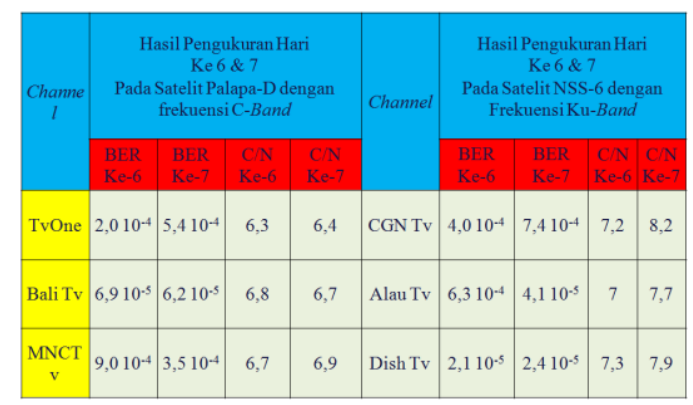

Gambar 6. Hasil Pengukuran C/N dan BER untuk CBand dan Ku-Band 


\section{KESIMPULAN}

1. Setelah melakukan pegambilan sample paramater BER \& C/N pada satelit Palapa-D dan NSS-6, maka diketahui bahwa semakin besar nilai $\mathrm{C} / \mathrm{N}$ yang dihasilkan, maka nilai BER cenderung semakin kecil. Begitu juga sebaliknya, apabila nilai $\mathrm{C} / \mathrm{N}$ semakin kecil, maka nilai BER cenderung semakin besar. Dengan kata lain, nilai $\mathrm{C} / \mathrm{N}$ berbanding terbalik dengan nilai BER. Dalam kata lain Semakin tinggi nilai $\mathrm{C} / \mathrm{N}$ maka akan semakin bagus pula sistem dari channel televisi tersebut. Ini berbanding terbalik dengan BER, dimana jika nilai BER semakin tinggi maka semakin buruk pula sistem dari channel televisi tersebut.

2. Dari pengambilan sampel yang dilakukan sebanyak 10 kali dalam 10 hari dimana masingmasing hari dilakukan pengambilan sampel sabanyak 1 kali pada setiap channelnya maka didapatkan nilai BER dan C/ N. Dari pengukuran tersebut diketahui bahwa nilai $\mathrm{C} / \mathrm{N}$ menampilkan hasil yang konstan dimana nilainya jarang berubah-ubah. Ini berbeda dengan BER ketika dilakukan pengukuran, nilai BER cenderung tidak konstan dimana nilainya sering berubah-ubah dalam setiap detik.

3. Setelah dilakukan pengukuran terhadap perilaku parameter BER dan C/N pada LNB Combo yang menggunakan teknologi DVB-S2, diketahui sinyal $\mathrm{C}$-Band mengalami penurunan kualitas, dan lebih terkonsentrasi pada Ku-Band. Ini dibuktikan dari hasil pengukuran yang telah dilakukan bahwa nilai parameter $\mathrm{C} / \mathrm{N}$ dan BER pada $\mathrm{Ku}-\mathrm{Band}$ lebih baik daripada nilai parameter BER dan $\mathrm{C} / \mathrm{N}$ pada C-Band.

\section{REFERENSI}

[1] Arif Kurniawan. Laporan Tugas Akhir Analisis Pengaruh Jumlah LNB pada Antena Parabola Terhadap Parameter C/N pada Aplikasi DVB-S. Purwokerto : Akademi Teknik Telekomunikasi Sandhy Putra Purwokerto, 2010.

[2] Chlorid Latifoso. Laporan Tugas Akhir Pengaruh Penggabungan LNB C-Band dengan LNB Ku-Band pada Antena Parabola Terhadap Parameter C/N pada Aplikasi DVB-S, Purwokerto : Akademi Teknik Telekomunikasi Sandhy Putra Purwokerto, 2010.

[3] Achmad Nasuha. Laporan Tugas Akhir Analisis Pengaruh Warna Antena Parabola Terhadap Parameter C/N pada Aplikasi DVB-S. Purwokerto : Akademi Teknik Telekomunikasi Sandhy Putra Purwokerto, 2011.

[4] T.L.H Simanjuntak. Sistem Komunikasi Satelit. Bandung : PT. Alumni, 2010.

[5] Walter Fischer. Handbook Digital Video and Audio Broadcasting Technology. Third Edition. Springer. 